\title{
A Review on Remdesivir: An Alternative Antiviral Drug to Fight against COVID-19
}

\author{
Nimesh Singh ${ }^{1 *}$, Bharat Suthar ${ }^{1}$, Abhay Mehta ${ }^{1}$, Sandeep Shukla ${ }^{2}$ and Archna Pandey ${ }^{2}$ \\ ${ }^{1}$ Flax Laboratories, M.H., India \\ ${ }^{2}$ Department of Chemistry, Dr. H.S. Gour University, Sagar, M.P., India
}

*Corresponding author: Nimesh Singh, Flax Laboratories, B-29/1, Mahad MIDC, Taluka- Mahad, Distt. - Raigad, M.H., India

\begin{abstract}
Coronavirus contamination that was found in mid-2019 has just hampered the world's motivation up until now. The quantity of irresistible cases has become worldwide to 35 lakhs thus the episode has been portrayed as a pandemic by the planet's wellbeing association, yet there have not been any "particular medications" or antibodies accessible to date. Applicable reports have distinguished a novel coronavirus with $80 \%$ homology. So there are not many signs accessible when different nations are utilizing the antiviral medication Remdesivir (anti-toxin). The particular antiviral medication routine for the treatment of patients with intense coronavirus infection 2019 (COVID-19) has not been demonstrated. Remdecivir (GS-5734), effectively pathogenic creature and human coronaviruses including intense respiratory condition coronavirus 2 (COVID-19) in vitro, and Center East respiratory disorder, NiR. - 1, and COVID-19 replication in creature models.
\end{abstract}

\section{Keywords}

Anti-viral drug, Remdesivir, COVID-19, SARS

\section{Introduction}

The pandemic of serious intense respiratory condition coronavirus 2 (COVID-19) has prompted in excess of 4692797 cases worldwide as of April 9, 2020. Half of Coronavirus Sickness 2019 (COVID-19) patients requiring negligibly intrusive mechanical ventilation regularly require hospitalization, and over-burden in medicinal services frameworks, particularly consideration units, are pervasive in many influenced nations.

Remdesivir is an anti-toxin created by an American organization known as biopharmaceutical Gilead. Is a nucleotide simple, an immediate simple of adenosine, which is embedded into the viral RNA chains, making its end untimely. Is being concentrated in 2020 as a treatment alternative after COVID-19 disease [1]. Gilead propelled a lab deriver preliminary against COVID-19, expressing that moves were demonstrated to be conflicting with SARS and MERS in creature models [2-4]. In Walk 2020, the a little development of remdesivir in rhesus macaque monkeys with COVID-19 sickness was found to repress ailment movement $[5,6]$. On January 21, 2020, the Wuhan Foundation of Virology applied for a Chinese patent for "COVID-19" [7]. On 18 Walk 2020 the planet Wellbeing Association (WHO) declared the dispatch of a four-arm wellbeing preliminary that could incorporate one gathering of patients treated with remdesivir $[8,9]$. While a partner study distributed in April 2020 recognized potential upgrades, seeing if or not this medication is successful requires randomized controlled preliminaries [10].

As of April 2020, remdesivir was seen the light of the fact that the most encouraging treatment for COVID-19 is Johns Hopkins College [11] and there have been a few progressing clinical preliminaries or calendars [12-22].

Gilead has started two Stage 3 clinical examinations to guarantee the wellbeing and adequacy of COVID-19-analyzed grown-ups following the audit and prompt endorsement of the new Gilead Examination (IND) medicate. These randomized, open-finished, multicenter coding considers started selecting patients in Walk 2020 and could enlist roughly 1,000 patients in

Citation: Singh N, Suthar B, Mehta A, Shukla S, Pandey A (2020) A Review on Remdesivir: An Alternative Antiviral Drug to Fight against COVID-19. Int J Virol AIDS 7:065. doi.org/10.23937/2469567X/1510065

Received: May 21, 2020: Accepted: June 18, 2020: Published: June 20, 2020

Copyright: (C) 2020 Singh N, et al. This is an open-access article distributed under the terms of the Creative Commons Attribution License, which permits unrestricted use, distribution, and reproduction in any medium, provided the original author and source are credited. 
the main period of the examination, in nations with the most elevated COVID-19.

\section{System of Activity}

Antiviral medications are a class of medications used to treat viral diseases [23]. Most antivirals are centered on explicit infections, while a wide antiviral is compelling against a decent rundown of infections [24]. Not at all like numerous anti-infection agents, anti-microbials don't devastate their pathogen; rather they upset their development.

Antiviral medications are a solitary class of antimicrobials, an enormous and compound gathering of anti-infection agents (likewise called antibacterial), antifungal and anti-parasite drugs, [25] or antiviral medications upheld by monoclonal antibodies [26]. Most antiviral operators are viewed as innocuous to the servant, and subsequently are frequently helpful. They ought to be isolated from the viricides, which are non-pharmacological however initiate or decimate viral particles, either inside or outside the body. Regular viricides are delivered by different plants, for example, eucalyptus and Australian tea trees [27].

\section{Infection Life Cycle}

Infections incorporate the quality and now and again catalysts that are put away in a protein-made case (called a capsid), and are at times secured with a lipid layer (once in a while called an 'envelope'). Infections can't recreate all alone and rather proliferate by smothering a number cell to flexibly their duplicates, subsequently delivering the people to come.

Scientists dealing with such "objective plan" techniques for the improvement of antiviral have attempted to assault infections at each phase of their life cycles. Mushrooms of certain species have been found to contain numerous antiviral synthetic compounds with synergistic impacts. Mixes disengaged from fruiting and shifted mushroom filtrates have wide range antiviral movement, yet the effective creation and accessibility of mixes, for example, bleeding edge antiviral might be a long way from being done [28]. Viral life cycles shift in their definite subtleties of the kind of infection; however they all offer a typical example:

1. Connection to a number cell.

2. Arrival of viral qualities and compounds into the host cell.

3. Replication of viral segments utilizing host-cell apparatus.

4. Get together of viral parts into complete viral cells.

5. Arrival of viral cells to contaminate new host cells.

Remdesivir as Key Medication to Treat COVID-19

Since the essential cases had been said in December
2019, defilement with the extreme intense breathing coronavirus 2 (COVID-19) has developed to be a worldwide pandemic $[29,30]$. Covid-19 - the sickness because of COVID-19 - is overpowering medicinal services frameworks globally [31,32]. The indications of COVID-19 tainting change generally, from asymptomatic affliction to pneumonia and dangerous intricacies, alongside intense breath wretchedness disorder, multisystem organ disappointment, and eventually, death [33-36]. More established victims and those with previous respiratory or cardiovascular circumstances have all the earmarks of being at the extraordinary risk for serious complications [34,35]. Inside the nonappearance of a demonstrated successful treatment, current administration comprises of strong consideration, comprising of obtrusive and noninvasive oxygen guide and cure with antibiotics $[36,37]$. Furthermore, numerous victims have gotten off-name or sympathetic use treatments, alongside antiretroviral, antiparasitic operators, calming mixes, and improving plasma [2,38-40].

Remdesivir can be a prodrug of a nucleotide simple that is intracellularly utilized to a simple of ATP that hinders viral RNA polymerases. Remdesivir has wide range of enthusiasm for resistance to members of various infection families, together with filoviruses (e.g., Ebola) and coronaviruses (e.g., Center East respiratory condition coronavirus [MERS-CoV]) and has demonstrated prophylactic and recuperating viability in nonclinical models of those coronaviruses [3,41-43]. In vitro giving a shot has moreover demonstrated that remdesivir has leisure activity contrary to COVID-19. Remdesivir seems to claim a top notch clinical security profile, as expressed on involvement with around 500 people, alongside healthy volunteers and victims dealt with for intense Ebola infection contamination [37,44], and bolstered by methods for our information (on record and imparted to the planet Wellbeing Association [WHO]). At some phase in this report, we depict results at some phase in a partner of patients hospitalized for extraordinary Covid-19 who have been managed with remdesivir on an empathetic use premise.

\section{Covid-19 Reason and Side Effects}

Covid-19 might be an ailment brought about by a totally extraordinary human-tainting beta coronavirus. The coronavirus was recognized in Wuhan city of Hubei Territory in China, utilizing cutting edge sequencing and continuous RT-PCR, in December 2019. The malady usually spreads through respiratory beads of the tainted individuals. The principal indications of the malady are fever, hack and brevity of breath. The individuals contaminated with novel coronavirus for the most part experience the ill effects of pneumonia.

\section{Remdesivir System of Activity}

Remdesivir is a $1^{\prime}$-cyano-subbed adenosine nucleotide simple with expansive range antiviral action against 


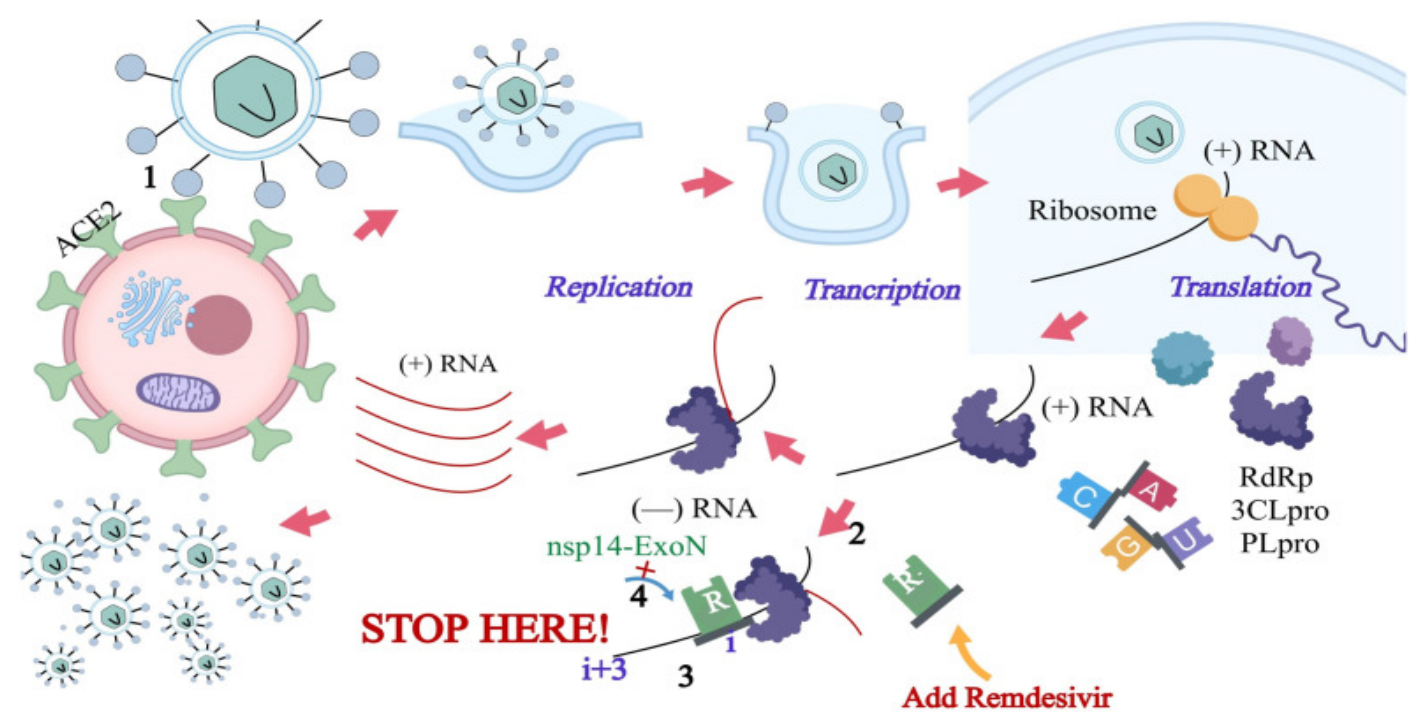

Figure 1: COVID-19 intrusion procedure and how remdesivir functions.

different RNA infections. The compound experiences a metabolic component, actuating nucleoside triphosphate metabolite for hindering viral RNA polymerases (Figure 1).

1) COVID-19 enters target cells by restricting the $S$ protein to the ACE2 receptor on the cell surface; 2 ) Remdeivir, the nucleotide analogs, go about as RdRp inhibitors, can give a plan to blocking RNA replication; 3) Once remdesivir included into the developing chain (I position), is can't cause a quick stop. Despite what might be expected, it will keep on stretching out three additional nucleotides down to stop the strand at $(I+3)$ position; 4) Remdesivir triphosphate can't be expelled by nsp14-ExoN [45].

\section{Conclusion}

Remdecivir might be a nucleotide simple item that is as of now being assessed in clinical preliminaries for the treatment of COVID-19. Preclinical examinations have demonstrated that remdecivir shows strong antiviral action against different Ebola virus strains. The intracellular degrees of NTP pools connected with expanded antiviral movement, the relating triphosphate being the dynamic kind of inhibitor and thus the viral RdRp target. Here we affirmed this affirmed hank and exhibited that remdecivir-TP is a substrate for the sanitized EBOV RdRp complex. Remdecivir-TP is an adenosine simple and in this way contends with ATP for combining. Be that as it may, the consolidated inhibitor doesn't go about as an arrangement eliminator. Hindrance of RNA amalgamation shows up primarily in the $I+5$ position. Regardless of unobtrusive arrangement subordinate impacts, RNA amalgamation generally finishes in the present. Expanding the grouping of the last nucleotide doesn't defeat this impact. Subsequently, it is sensible to presume that the postponed chain end is the fundamental driver of the antiviral activity of remedicavir.

Until this point, no treatment adequacy has been shown for patients with Covid-19. This primer report depicts clinical results during a little arrangement of patients who were fundamentally sick and treated with Remedicivir with Covid-19. Information from a few continuous randomized, controlled preliminaries will before long give additional data about the security and viability of Remedicivir for Covid-19, be that as it may, the outcomes saw in this humane use program are right now the easiest information accessible. Specifically, an improvement in oxygen-bolster status was seen in $68 \%$ of patients, and by and large mortality was $13 \%$ over the 18-day middle development. In an ongoing randomized, controlled preliminary of lopinavir-ritonavir in patients hospitalized for Covid-19, 28-day mortality was $22 \%$ [46].

No new wellbeing signals were found during the present moment remedicavir treatment during this humane use accomplice. Nonclinical toxicology examines have demonstrated renal impedance; however nephrotoxicity because of remedicavir treatment stays muddled. Gentle to direct heights were seen in ALT, AST, or both during the companion of patients with extreme Covid-19, as announced in concentrates in solid volunteers and Ebola-contaminated patients [45,47-49].

\section{References}

1. Brunk D (2020) Remdesivir under study as treatment for novel coronavirus. Medscape.

2. de Wit E, Feldmann F, Cronin J, Jordan R, Okumura A, et al. (2020) Prophylactic and therapeutic remdesivir (GS5734) treatment in the rhesus macaque model of MERSCoV infection. Proc Natl Acad Sci USA 117: 6771-6776.

3. Sheahan TP, Sims AC, Graham RL, Menachery VD, Gralinski LE, et al. (2017) Broad-spectrum antiviral GS-5734 inhibits both epidemic and zoonotic coronaviruses. Sci Transl Med 9: eaal3653.

4. Joseph SS, Samuel M (2020) Gilead working with China to test Ebola drug as new coronavirus treatment. Thomson Reuters.

5. Munster V, Feldmann F, Williamson B, Van Doremalen N, 
Perez-Perez L, et al. (2020) Respiratory disease and virus shedding in rhesus macaques inoculated with SARSCOV-2. bioRxiv.

6. Williamson B, Feldmann F, Schwarz B, Meade-White K, Porter D, et al. (2020) Clinical benefit of remdesivir in rhesus macaques infected with COVID-19. bioRxiv.

7. Solidarity clinical trial for COVID-19 treatments (2020) WHO.

8. UN health chief announces global 'solidarity trial' to jumpstart search for COVID-19 treatment (2020) UN news.

9. Grein J, Ohmagari N, Shin D, Diaz G, Asperges E, et al (2020) Compassionate use of remdesivir for patients with severe Covid-19. N Engl J Med 382: 2327-2336.

10. Auwaerter PG (2020) Coronavirus COVID-19 (COVID-19). Johns Hopkins ABX Guide.

11. Remdesivir clinical trials (2020). Gilead Sciences.

12. 7 Studies found for: Remdesivir \& Recruiting, Not yet recruiting, Active, not recruiting, Completed, Enrolling by invitation Studies \& COVID-19. (2020) ClinicalTrials.gov. U.S. National Library of Medicine.

13. A Trial of remdesivir in adults with severe COVID-19 (2020). ClinicalTrials.gov.

14. A Trial of remdesivir in adults with mild and moderate COVID-19 (2020). ClinicalTrials.gov.

15. Study to evaluate the safety and antiviral activity of remdesivir (GS-5734) in participants with moderate coronavirus disease (COVID-19) compared to standard of care treatment (2020). ClinicalTrials.gov.

16. Study to evaluate the safety and antiviral activity of remdesivir (gs-5734) in participants with severe coronavirus disease (COVID-19) (2020). ClinicalTrials.gov.

17. Adaptive COVID-19 treatment trial (ACTT) (2020). ClinicalTrials.gov.

18. Trial of treatments for COVID-19 in hospitalized adults (DisCoVeRy) (2020). ClinicalTrials.gov.

19. Expanded access remdesivir (RDV; GS-5734) (2020). ClinicalTrials.gov.

20. Expanded access treatment protocol: Remdesivir (RDV; GS-5734) for the treatment of SARS-CoV2 (CoV) infection (COVID-19) (2020). ClinicalTrials.gov.

21. Multi-centre, adaptive, randomized trial of the safety and efficacy of treatments of COVID-19 in hospitalized adults (DisCoVeRy) (2020). European Union Clinical Trials Register.

22. Barmann J (2020) Bay area-based gilead sees potential legal conflict with china over its coronavirus drug (2020). SFist.

23. (2020) Medmicro Chapter 52. Archived from the original on 18 August 2000.

24. Rossignol JF (2014) Nitazoxanide: A first-in-class broad-spectrum antiviral agent. Antiviral Res 110: 94-103.

25. Kisung Ko, Yoram Tekoah, Pauline M Rudd, David J Harvey, Raymond A Dwek, et al. (2003) Function and glycosylation of plant-derived antiviral monoclonal antibody. PNAS 100: 8013-8018.

26. Schnitzler P, Schön K, Reichling J (2001) Antiviral activity of Australian tea tree oil and eucalyptus oil against herpes simplex virus in cell culture. Pharmazie 56: 343-347.

27. Lindequist U, Niedermeyer THJ, Jülich WD (2005) The pharmacological potential of mushrooms. Evid Based Complement Alternat Med 2: 285-299.

28. Cucinotta D, Vanelli M (2020) WHO declares COVID-19 a pandemic. Acta Biomed 91: 157-160.

29. Spinelli A, Pellino G (2020) COVID-19 pandemic: Perspectives on an unfolding crisis. Br J Surg 107: 785-787.

30. Fauci AS, Lane HC, Redfield RR (2020) Covid-19 - Navigating the uncharted. N Engl J Med 382: 1268-1269.

31. Mahase E, Kmietowicz Z (2020) Covid-19: Doctors are told not to perform CPR on patients in cardiac arrest. BMJ 368: m1282.

32. Rodriguez-Morales AJ, Cardona-Ospina JA, Gutiérrez-Ocampo E, Pena RV, Rivera YH, et al. (2020) Clinical, laboratory and imaging features of COVID-19: A systematic review and meta-analysis. Travel Med Infect Dis 34: 101623.

33. Weiss P, Murdoch DR (2020) Clinical course and mortality risk of severe COVID-19. Lancet 395: 1014-1015.

34. Wu C, Chen X, Cai Y, Xia J, Zhou X, et al. (2019) Risk factors associated with acute respiratory distress syndrome and death in patients with coronavirus disease 2019 pneumonia in Wuhan, China. JAMA Intern Med e200994.

35. Onder G, Rezza G, Brusaferro S (2020) Case-fatality rate and characteristics of patients dying in relation to COVID-19 in Italy. JAMA

36. Poston JT, Patel BK, Davis AM (2020) Management of critically ill adults with COVID-19. JAMA.

37. Cao B, Wang Y, Wen D, Liu W, Wang J, et al. (2020) A trial of lopinavir-ritonavir in adults hospitalized with severe Covid-19. N Engl J Med 382.

38. Shen C, Wang Z, Zhao F, Yang Y, Li J, et al. (2020) Treatment of 5 critically ill patients with COVID-19 with convalescent plasma. JAMA 323: 1582-1589.

39. Touret $F$, de Lamballerie $X$ (2020) Of chloroquine and COVID-19. Antiviral Res 177: 104762.

40. Baden LR, Rubin EJ (2020) Covid-19- The search for effective therapy. N Engl J Med 382: 1851-1852.

41. Sheahan TP, Sims AC, Leist SR, Schafer A, Won J, et al. (2020) Comparative therapeutic efficacy of remdesivir and combination lopinavir, ritonavir, and interferon beta against MERS-CoV. Nat Commun 11: 222.

42. Wang M, Cao R, Zhang L, Yang X, Liu J, et al. (2020) Remdesivir and chloroquine effectively inhibit the recently emerged novel coronavirus (2019-nCoV) in vitro. Cell Res 30: $269-271$.

43. Mulangu S, Dodd LE, Davey RT Jr, Mbaya OT, Proschan $\mathrm{M}$, et al. (2019) A randomized, controlled trial of Ebola virus disease therapeutics. N Engl J Med 381: 2293-2303.

44. European Medicines Agency (2020). Summary on compassionate use: Remdesivir Gilead.

45. Pradeep P, Manju V, Ahsan MF (2019) Antiviral Potency of Mushroom Constituents. Medicinal Mushrooms 275-297.

46. Cao YC, Deng QX, Dai SX (2020) Remdesivir for severe acute respiratory syndrome coronavirus 2 causing COVID-19: An evaluation of the evidence. Travel Med Infect Dis. 2: 101647.

47. Nema N, Pandey A, Singh N, Suthar B, Mehta A (2020) Corona Virus: An immunological perspective review. Int $\mathrm{J}$ Immunol Immunother 7: 1-6.

48. Pandey A, Singh N, Shukla S (2020) Re-infection and immunological effect of corona virus: A detailed review. Indo Global Journal of Pharmaceutical Sciences 10: 25-32.

49. Mehta A, Singh N, Pandey A, Suthar B (2020) Spike protein based vaccine and chemical drugs: Futuristic weapon to fight against pandemic COVID 19. Alochana Chakra Journal 9: 36-42. 